\title{
DELITOS CONTRA LA EFICIENCIA DE LA ADMINISTRACIÓN PÚBLICA ECUATORIANA. CASO DE ESTUDIO: MORONA SANTIAGO
}

\section{CRIMES AGAINST THE EFFICIENCY OF THE ECUADORIAN PUBLIC ADMINISTRATION. CASE STUDY: MORONA SANTIAGO}

\author{
Ana Alexandra López Jara ${ }^{1}$
}

\section{RESUMEN}

Los delitos contra la administración pública se han convertido en un tema de interés y análisis para las entidades de control gubernamental a fin de transparentar la eficiencia en la administración de los recursos públicos. En el Estado ecuatoriano, por una parte, la Contraloría General del Estado es el ente de control, quien mediante exámenes de auditoría evalúa la gestión financiera pública, y, por otra parte, la Fiscalía General del Estado es quien investiga y procesa judicialmente los delitos determinados por el ente de control. En este estudio se describen los principales delitos contra la administración pública investigados por la Fiscalía provincial de Morona Santiago desde enero del 2014 a junio del 2018.
Palabras clave: administración pública, delitos financieros, auditoría forense, corrupción, gestión pública.

\section{ABSTRACT}

Crimes against the public administration have become a topic of interest and analysis for government control entities in order to make the administration of public resources more efficient. In the Ecuadorian state, the General Comptroller of the State is the control entity, who through auditing exams evaluates public financial management and, on the other hand, the State Attorney General's Office investigates and prosecutes the crimes determined by the control entity. In this investigation, they describe the main crimes against the public admi-

1 Ingeniera en Contabilidad y Auditoría, magíster en Auditoría Integral. Profesora titular de la carrera de Contabilidad y Auditoría de la Universidad Católica de Cuenca.

Correo electrónico: annylopezjara@hotmail.com

Orcid: 0000-0001-6905-9025

Código JEL: G38, K19, M14, H 83, H70.

Fecha de recepción: 19/07/2018

Fecha de aprobación: 9/08/2018

DOI: https://doi.org/10.18601/16577175.n22.09 
nistration investigated by the Provincial Prosecutor's Office of Morona Santiago in the period January 2014 to June 2018. Keywords: public administration, financial crimes, forensic audit, corruption, public management.

\section{INTRODUCCIÓN}

La administración pública en las últimas décadas ha presentado numerosos casos de corrupción que violentan la integridad de los principios y normas destinados a precautelar los recursos públicos, siendo necesario el fortalecimiento de los controles internos en las organizaciones.

Para tal efecto la Constitución de la República del Ecuador (2008) caracteriza los servicios públicos como una asistencia a la colectividad que se rige por los principios de eficacia, eficiencia, calidad, transparencia y evaluación. Por tanto, los funcionarios y servidores públicos tienen la responsabilidad de administrar los recursos en orden a estos principios y con sujeción a responsabilidades de tipo administrativa, civil e indicios de responsabilidad penal que acarrea el incumplimiento.

Explica además que las responsabilidades a las que se encuentra sujeto el servidor público y la investigación de los delitos de la administración pública es competencia de la Fiscalía General del Estado (FGE), mientras que la declaración de una sentencia es función del Consejo de la Judicatura; estas dos instancias en el Ecuador tienen dependencias provinciales para agilitar y transparentar la justicia. El objetivo de este estudio es determinar los principales delitos de la administración pública en la provincia de Morona Santiago y el estado procesal de los casos investigados en el periodo de enero del 2014 a junio del 2018.

La auditoría forense en respuesta a los delitos de la administración pública

La corrupción es un fenómeno característico de las sociedades humanas que ocurre tanto en países en vias de desarrollo como en países desarrollados y ha estado asociado al sector público. En el caso de Colombia, el fenómeno de corrupción política es reproducido por la debilidad institucional del país y por las condiciones sociopolíticas y culturales como el clientelismo y el tráfico de drogas (Camisón y Moreno, 2018).

Los recursos públicos en cualquier nación presentan un alto porcentaje de riesgo para el desarrollo de fraudes finacieros, debido, por una parte, a las cifras económicas que administran, y, por otra, a las debilidades en el control interno institucional. En la búsqueda de elementos que permitan evitar la corrupción, los resultados parten desde del fortalecimiento del control interno hasta la determinación de responsabilidades penales por la inobservancia a la normativa legal.

López y Pesantez (2016) consideran que las organizaciones en orden con el desarrollo científico y tecnológico han modificado sus estructuras en función a los cambios requeridos, entre ellos han centrado la atención en el diseño de controles internos que promuevan la 
eficiencia en las operaciones, la salvaguarda de activos y la reducción de los riesgos. Por otra parte, la investigación realizada en España por Pérez (2018) sugiere, como respuesta para combatir la corrupción, extrapolar elementos e instituciones de programas de cumplimiento en las empresas a las estructuras de las administraciones públicas y determinar las responsabilidades penales.

En este mismo sentido, Benito, Guillamón, Ríos y Bastida (2018) afirman que el nivel de ingresos, la desigualdad de ingresos, el nivel educativo, los ingresos urbanos municipales y la naturaleza turística afectan a la corrupción. Además, reconoce que los salarios relativamente más altos no reducen los incentivos de los políticos para ser corruptos y que en la gestión pública de políticos con miras a ser reelectos la corrupción disminuye. Por tanto, la legislación penal debe orientarse a sancionar todo acto que afecte la integridad de la administración pública.

En atención a la problemática de los riesgos el control interno en las organizaciones públicas empieza a tomar importancia como medida para la consecución de los objetivos, sin embargo, a pesar de las innovaciones en los diferentes modelos de control, el fraude ha impactado los resultados financieros en las organizaciones dando origen al fortalecimiento de la legislación administrativa y penal en cada país.

Visto de esta forma, a partir de la legislación orientada a sancionar actos $\mathrm{y}$ hechos relativos al fraude surge el interes para las empresas en investigar la cuantía del delito, los involucrados, el motivo y las condiciones en las que se desarrollaron los hechos, siendo así la auditoria forense considerada para la administración como un elemento de control y asesoría tanto para entidades públicas como privadas.

De las evidencias bibliograficas investigadas se conoce que el origen de la auditoría forense surge del estudio de los actos de corrupción que involucran la intervención del Estado, visto de otra manera corresponden a delitos financieros que en ese entonces no eran sujetos de responsabilidad, debido a que el marco normativo no garantizaba transparencia en la información financiera. En relación con este hecho se derivan las primeras normas orientadas a fortalecer los sistemas contables y financieros en las organizaciones.

Por otra parte, en la investigación realizada por Torres (2013) reconoce como evidencia del inicio de la auditoría forense el código Hammurabi creador en 1780 a. de C. Este documento era conocido como la primera ley en la antigua Mesopotamia, con 126 fagmentos demostraba que la auditoría forense busca evidenciar con documentacion contable un fraude o mentira en los resultados contables y económicos de las operaciones mercantiles.

Más adelante, en los años treinta la auditoría forense empieza a ejercerse informalmente, cuando un contador que trabajaba en el departamento de impuestos de la organización de Al Capone desenmascaró a su creador Alphonse Gabriel, quien se dedicaba al lavado de 
dinero y a otros crímenes, las leyes del momento no sancionaban esta actividad como un delito y se mantuvo al margen de la ley. A partir de este hecho, con el propósito de incrementar los niveles de confianza y seguridad en las operaciones contables, se impulsó la creacion del Comité de Normas Internacionales de Contabilidad (IFAC), en junio de 1973, y las Normas Internacionales de Auditoría (NIAS).

Sobre este asunto Cano y Castro (2004) definen a la auditoría forense como una auditoria especializada en descubrir, divulgar y atestar sobre fraudes y delitos en el desarrollo de las funciones públicas considerándose un verdadero apoyo a la tradicional auditoria gubernamental, en especial ante delitos tales como enriquecimiento ilícito, peculado, cohecho, soborno, desfalco, malversación de fondos, prevaricato, entre otros.

De la revisión bibliográfica realizada a los siguientes autores Fontán (2009); Badillo (2012); Cárdenas y Becerra (2013); Hortal y Bautista (2013); Ramírez y Bohórquez (2013); Salinas (2014); Quintinilla y Mendoza (2015); Rey (2016) y Torres, Jaramillo y Cuenca (2016) se concluye que la auditoría forense es la búsqueda y aplicación de procedimientos que permiten obtener evidencias sobre la cuantía del fraude, los efectos directos e indirectos, la posible tipificación, los presuntos autores, cómplices y encubridores relacionados al delito que servirán de fundamento para el análisis en las instancias judiciales. Partiendo de los supuestos anteriores, la auditoría forense se orienta a la detección de fraudes, sin embargo, existe evidencia bibliográfica que reconoce también el quehacer de la auditoría hacia la prevención del fraude financiero, bajo este enfoque se sugiere la siguiente clasificación: auditoría forense preventiva y auditoría forense detectiva.

La auditoría forense preventiva está orientada a proporcionar aseguramiento (evaluación) o asesoría a las organizaciones respecto de su capacidad para disuadir, prevenir (evitar), detectar y reaccionar ante fraudes financieros; puede incluír trabajos de consultoría para implementar: programas y controles antifraude, esquemas de alerta temprana de irregularidades. Mientras que la auditoría forense detectiva está orientada a identificar la existencia de fraudes financieros mediante la investigación profunda de estos llegando a establecer entre otros aspectos los siguientes: cuantía del fraude, efectos directos e indirectos, posible tipificación (según normativa penal aplicable), presuntos autores, cómplices y encubridores.

Atendiendo a estas consideraciones la auditoría preventiva provee de asesoría para el cumplimiento de las operaciones administrativas y financieras en orden con las leyes contables y tributarias pertinentes. No obstante, la función de la auditoría forense actúa también de manera posterior a los hechos que provocaron pérdidas financieras, determinando los elementos del fraude que permitan evidenciar el delito ante los tribunales judiciales, tal como se ha indicado antes. 
Desde la perspectiva de la administración pública Duarte (2015) y Torres, Jaramillo y Cuenca (2016) argumentan que el campo de la auditoría forense es la investigación de delitos financieros, cuyos responsables son dignatarios, funcionarios, ejecutivos, empleados que desempeñan actividades o funciones en entes públicos o privados, en muchos casos, con ayuda de personas externas, sean proveedores, familiares cercanos, clientes, testaferros, entre otros. De este modo, concluyen que la auditoría forense es exclusiva del sector público, pero en el sector privado la globalización obliga a las compañías a prepararse para administrar los riesgos y para descubrir y prevenir los diferentes tipos de delitos.

Como se ha analizado hasta el momento, por una parte, el reconocimiento de la auditoría tradicional hacia la auditoría forense ha logrado impulsar normativas que penalicen los actos de corrupción en la administración pública. Es así que la Constitución de la República del Ecuador (2008) ha encargado el control y fiscalización de los recursos públicos a la Contraloría General del Estado y, por medio de este, la emisión de normativas legales para los efectos administrativos, financieros y de control interno en las entidades públicas. Por otra parte, el Estado ecuatoriano mediante el Código Orgánico Integral Penal (2016) ha dispuesto las sanciones privativas de libertad para conductas delitivas que incluyen los delitos contra de la administración pública.

Es decir, la Contraloría General del Estado mediante auditorías financieras garantiza la eficiencia en la admi- nistración de los recursos públicos y establece responsabilidades de tipo administrativa, civil o indicios de responsabilidad penal. La determinación de la resposabilidad penal en los servidores públicos corresponde a las instancias judiciales en función al Código Orgánico Integral Penal, tal como se ha mencionado antes, este que en la sección tercera establece como los delitos contra la eficiencia de la administración pública los siguientes: el peculado, el enriquecimiento ilícito, el cohecho, la concusión, el incumplimiento de decisiones legítimas de autoridad competente, el ataque o resistencia, la ruptura de sellos, el tráfico de influencias, la oferta de realizar tráfico de influencias, la usurpación y simulación de funciones públicas, el uso de fuerza pública contra órdenes de autoridad, el testaferrismo, entre otros.

A partir del informe de auditoría emitido por la Contraloría General del Estado (CGE), que conlleve indicios de responsabilidad penal, se inicia una investigación en la Fiscalía General del Estado (FGE) y se continúa con proceso judicial en instancias del Consejo de la Judicatura.

La FGE mediante una investigación previa obtiene las evidencias de carácter financiero y administrativo que permiten obtener certeza sobre los hallazgos presentados en el informe de auditoría, de manera puntual sobre el delito financiero que implica al procesado. Esta causa da paso a la formulación de cargos de acuerdo con el Código Orgánico Ingral Penal, para efectos, la investigación fiscal dura noventa días 
antes al señalamiento de la audiencia preparatoria o juicio.

La siguiente instancia en la que se determina la responsabilidad penal sobre el acusado recae en los tribunales de justicia del Consejo de la Judicatura, en la que mediante una audiencia el juez analiza las evidencias procesadas y dictamina una sentencia condenatoria o de inocencia. De estar el procesado inconforme con la resolución del juez previa solicitud motivada en términos de derecho presenta el recurso de apelación ante la sala de justicia provincial o nacional para que el caso sea nuevamente investigado (ver diagrama 1).

Diagrama 1.

Tratamiento procesal para fraudes financieros en el Consejo de la Judicatura

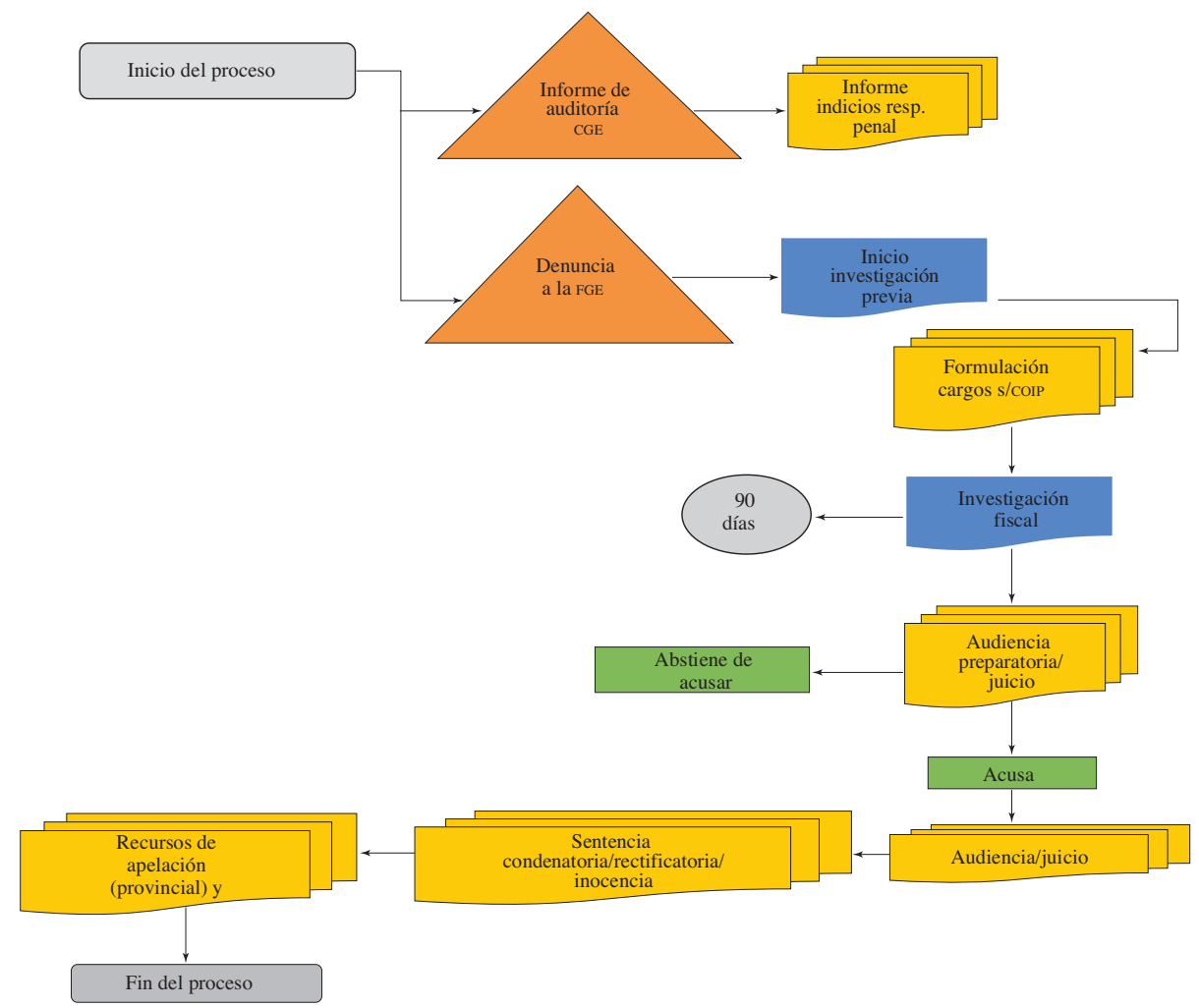

Fuente: Rivadeneira (2018).

A continuación (ver cuadro 1), se describe brevemente los principales delitos contra la eficiencia en la administración pública tipificados en el Código Orgánico Integral Penal (2016). 
Cuadro 1.

Delitos contra la eficiencia en la administración pública ecuatoriana

\begin{tabular}{|c|c|}
\hline Peculado & Enriquecimiento ilícito \\
\hline $\begin{array}{l}\text { Es la conducta caracterizada por los servidores públi- } \\
\text { cos, quienes en beneficio propio o de terceros abusen, } \\
\text { se apropien, distraigan o dispongan arbitrariamente } \\
\text { de bienes muebles o inmuebles, dineros públicos o } \\
\text { privados, o documentos que estén en su poder en virtud } \\
\text { o razón de su cargo. }\end{array}$ & $\begin{array}{l}\text { Se reconoce este comportamiento en los servidores } \\
\text { públicos que hayan obtenido para sí o para terceros } \\
\text { un incremento patrimonial injustificado a su nombre } \\
\text { producto de su cargo o función, superior a cuatrocientos } \\
\text { salarios básicos unificados del trabajador en general. }\end{array}$ \\
\hline Cohecho & Concusión \\
\hline $\begin{array}{l}\text { Este delito sanciona la conducta de los servidores pú- } \\
\text { blicos que reciban o acepten, por sí o por interpuesta } \\
\text { persona, beneficio económico indebido o de otra clase } \\
\text { para sí o un tercero, sea para hacer, omitir, retardar o } \\
\text { condicionar cuestiones relativas a sus funciones. }\end{array}$ & $\begin{array}{l}\text { Los servidores públicos que abusando de su cargo o } \\
\text { funciones, por sí o por medio de terceros, ordenen o } \\
\text { exijan la entrega de derechos, cuotas, contribuciones, } \\
\text { rentas, intereses, sueldos o gratificaciones no debidas. }\end{array}$ \\
\hline $\begin{array}{l}\text { Incumplimiento de decisiones legítimas de autoridad } \\
\text { competente }\end{array}$ & Ataque o resistencia \\
\hline $\begin{array}{l}\text { La persona que incumpla órdenes, prohibiciones espe- } \\
\text { cíficas o legalmente debidas dirigidas a ella por autori- } \\
\text { dad competente en el marco de sus facultades legales. }\end{array}$ & $\begin{array}{l}\text { La persona que ataque o se resista con violencias o } \\
\text { amenazas a los empleados públicos, a los depositarios } \\
\text { o agentes de la fuerza pública, cuando obran en ejecu- } \\
\text { ción de las leyes, o de las órdenes o reglamentos de la } \\
\text { autoridad pública }\end{array}$ \\
\hline Ruptura de sellos & Usurpación y simulación de funciones públicas \\
\hline $\begin{array}{l}\text { Incurre en este delito la persona que rompa o retire } \\
\text { los sellos impuestos por la autoridad competente, para } \\
\text { incumplir la medida impuesta. }\end{array}$ & $\begin{array}{l}\text { Es sujeto de responsabilidad penal la persona que ejerza } \\
\text { funciones públicas sin autorización o simule cargo o } \\
\text { función pública, será sancionada con pena privativa } \\
\text { de libertad. }\end{array}$ \\
\hline Tráfico de influencias & Uso de fuerza pública contra órdenes de autoridad \\
\hline $\begin{array}{l}\text { Este hecho se presenta cuando los servidores públi- } \\
\text { cos, y prevaliéndose de las facultades de su cargo o } \\
\text { de cualquier otra situación derivada de su relación } \\
\text { personal o jerárquica, ejerza influencia en otra u otro } \\
\text { servidor para obtener un acto o resolución favorable a } \\
\text { sus intereses o de terceros. }\end{array}$ & $\begin{array}{l}\text { Se sanciona la conducta de los servidores públicos que } \\
\text { utilice a miembros de la Policía Nacional o Fuerzas } \\
\text { Armadas contradiciendo la Constitución, impidiendo la } \\
\text { ejecución de órdenes legítimas expedidas por autoridad } \\
\text { competente o permitiendo el uso de la violencia sin } \\
\text { legitimación legal suficiente. }\end{array}$ \\
\hline \multicolumn{2}{|c|}{ Testaferrismo } \\
\hline $\begin{array}{l}\text { a conducta corresponde a las personas que consient } \\
\text { los, acciones, participaciones, dinero, valores o ef }\end{array}$ & $\begin{array}{l}\text { a en aparentar como suyos bienes muebles, inmuebles, } \\
\text { ctos que lo representen, producto del enriquecimiento } \\
\text { cto del enriquecimiento privado no justificado. }\end{array}$ \\
\hline
\end{tabular}

Fuente: Código Orgánico Integral Penal (2016).

\section{MATERIALES Y MÉTODOS}

\section{La presente investigación es de natura-} leza exploratoria y de tipo descriptiva, debido a que determina los principales delitos contra la eficiencia de la administración pública y el estado procesal de los casos investigados en la provincia de Morona Santiago.

Para efectos de la clasificación de los delitos y los diferentes estados procesales, mediante el uso de técnicas bibliográficas, se realizó una revisión 
física y documental a los archivos que reposan en la dependencia de la Fiscalía General del Estado en Morona Santiago. El número de casos revisados fueron 370, que corresponden al periodo comprendido entre enero del 2014 hasta junio del 2018; siendo considerados como el universo total de la investigación. Además, de esta técnica se realizaron entrevistas a servidores públicos de la Fiscalía General del Estado y del Consejo de la Judicatura para justificar las razones de los diferentes estados procesales indicados en los casos investigados.

\section{RESULTADOS Y DISCUSIÓN}

De la revisión física y documental realizada a los archivos de la Fiscalía General del Estado en Morona Santiago se encontró un total de trescientos sesenta casos sobre delitos contra la eficiencia de la administración pública segmentados en los siguientes: peculado, cohecho, incumplimiento de decisiones, ataque o resistencia y ruptura de sellos. A continuación, se presenta el estado de investigación judicial de los delitos investigados en los últimos cuatro años en Morona Santiago (ver tabla 1).

Tabla 1.

Delitos en contra de la eficiencia de la administración pública en Morona Santiago (2014-2018)

\begin{tabular}{|c|c|c|c|c|c|}
\hline Estado Procesal & Peculado & Cohecho & $\begin{array}{c}\text { Incumplimiento } \\
\text { de decisiones } \\
\text { legítimas de la } \\
\text { autoridad } \\
\text { competente } \\
\end{array}$ & $\begin{array}{l}\text { Ataque o } \\
\text { resistencia }\end{array}$ & $\begin{array}{l}\text { Ruptura } \\
\text { de sellos }\end{array}$ \\
\hline Sentencia & 7 & & 4 & 2 & \\
\hline Mixta & 2 & & & & \\
\hline Auto llamamiento a juicio & 2 & & & & \\
\hline Apelación & 3 & & 2 & & \\
\hline Archivados & 3 & 1 & 8 & 1 & \\
\hline Recurso de hecho & 1 & & & & \\
\hline Investigación previa & 5 & 2 & 244 & 25 & 3 \\
\hline Ratificación de inocencia & & & 3 & & \\
\hline Condenatorio & & & 1 & 2 & \\
\hline Principio de oportunidad & & & 3 & & \\
\hline Procedimiento abreviado & & & 1 & 2 & \\
\hline Procedimiento directo & & & 1 & 1 & \\
\hline Extinción del ejercicio de acción penal & & & 3 & & \\
\hline Instrucción & & & 6 & & 1 \\
\hline Llamamiento a juicio & & & 15 & 2 & \\
\hline Seguimientos & & & & 4 & \\
\hline Total & 23 & 3 & 291 & 39 & 4 \\
\hline
\end{tabular}

Fuente: archivos de la Fiscalía de Morona Santiago, 2018. 
El peculado es el tercer delito altamente investigado en las instancias judiciales en Morona Santiago del análisis estadístico realizado se conoce que el $30 \%$ del total de casos denunciados o investigados por efectos de auditorías financieras forenses son sentenciados con pena privativa de libertad.

Al investigar los motivos por los cuales la eficiencia en las instancias judiciales no son mayores, se conoce que anterior a todo inicio de investigación por delitos financieros existe la evidencia de auditoría competente, pertinente y relevante que demuestra la cuantía del delito y los impactos sobre los estados financieros, sin embargo el $22 \%$ se mantienen en investigación previa, a órdenes del fiscal y el $13 \%$ de los casos son archivados por no disponer de los suficientes elementos de convicción para que el fiscal continúe con la investigación. En un porcentaje igual a los casos archivados se ubican los casos en apelación, es decir, el acusado en uso de sus derechos ha presentado un recurso intermedio en razón de no estar de acuerdo con la sentencia emitida por el juez.

En suma, la investigación en instancias judiciales demuestra letargo en "la investigación previa", únicamente el $30 \%$ del total de casos presentados por peculado termina con sentencia condenatoria y por un porcentaje significativo proceden al recurso de apelación por inconformidad de la decisión del juez. Es necesario vincular acciones entre la Contraloría General del Estado y la Fiscalía General del Estado para evitar el retazo en la investigación nuevamente de los delitos financieros enviados por indicios de responsabilidad de los informes de contraloría a fin de agilizar los procesos de justicia y demostrar el apoyo procesal que otorga la CGE (Gráfico 2)

Gráfico 2.

Casos de peculado en Morona Santiago

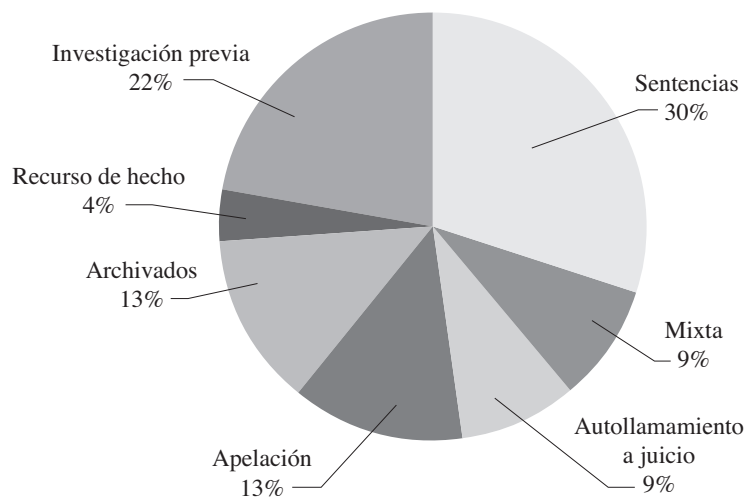


El cohecho es el delito contra la administración pública que menores casos presenta en los últimos cuatro años en Morona Santiago, conocido este delito comúnmente por la aceptación de sobornos por parte de los funcionarios públicos; el $75 \%$ de los casos se encuentran en investigación previa, es decir, en la búsqueda de elementos probatorios que evidencien el caso, este proceso puede durar hasta un año. Por otra parte, el $25 \%$ de investigaciones judiciales que penalizan esta conducta han sido archivados en virtud de que no existen los suficientes elementos para formular cargos o, a su vez, las partes no han brindado las facilidades para que el proceso continúe (gráfico 3 ).

Gráfico 3.

Casos de cohecho en Morona Santiago

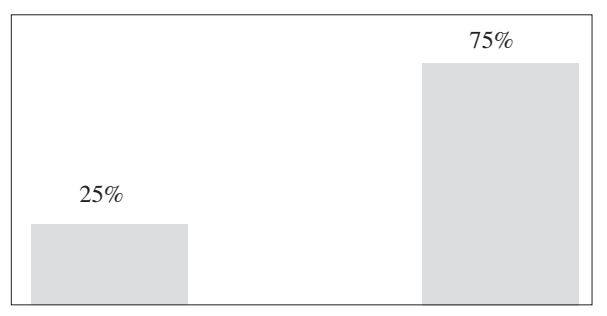

Archivada

Investigación

Fuente: archivos de la Fiscalía de Morona Santiago, 2018.

El incumplimiento de decisiones legítimas de la autoridad competente presenta el mayor número de casos investigados en la provincia de Morona Santiago, este delito recibe un tratamiento legalmente distinto si es efectuado por un ciudadano o si lo es por un servidor militar o policial. En esta investigación, se presentan los casos relativos al incumplimiento de órdenes y prohibiciones específicas cometidos por los servidores públicos dentro de sus funciones. Es importante resaltar que la Constitución de la República (2008) reconoce a todo ciudadano el derecho a la resistencia frente a acciones del poder público que vulneren o puedan vulnerar sus derechos (art. 98), por lo que el ciudadano que intente resistir una orden o prohibición específica, por esta razón, podría ser procesado y aun condenado por este delito.

De los resultados se conoce que el $84 \%$ de los casos se encuentran en investigación previa mediante la toma de pruebas para obtener información sobre el delito del procesado y solo el $5 \%$ de los casos han fijado fecha para un juicio. Por otra parte, el $3 \%$ de los casos procesado se encuentran archivados por falta de evidencias o colaboración de las partes para el desarrollo de la investigación. Finalmente, se conoce que de 291 casos investigados por este delito, únicamente cuatro han obtenido sentencia y un solo caso ha sido calificado como condenatorio bajo una pena privativa de libertad de uno a tres años (gráfico 4)

El delito de ataque o resisten se ubica en el segundo delito con mayores casos investigados en Morona Santiago, esta conducta deriva de usuarios de los servicios públicos que ataquen o se resistencia con violencias o amenazas a los empleados públicos.

De la investigación se conoce que la etapa procesal en la que reposan la mayor cantidad de casos es la "investigación previa", en efecto, para 


\section{Gráfico 4.}

Incumplimiento de decisiones legítimas de la autoridad competente

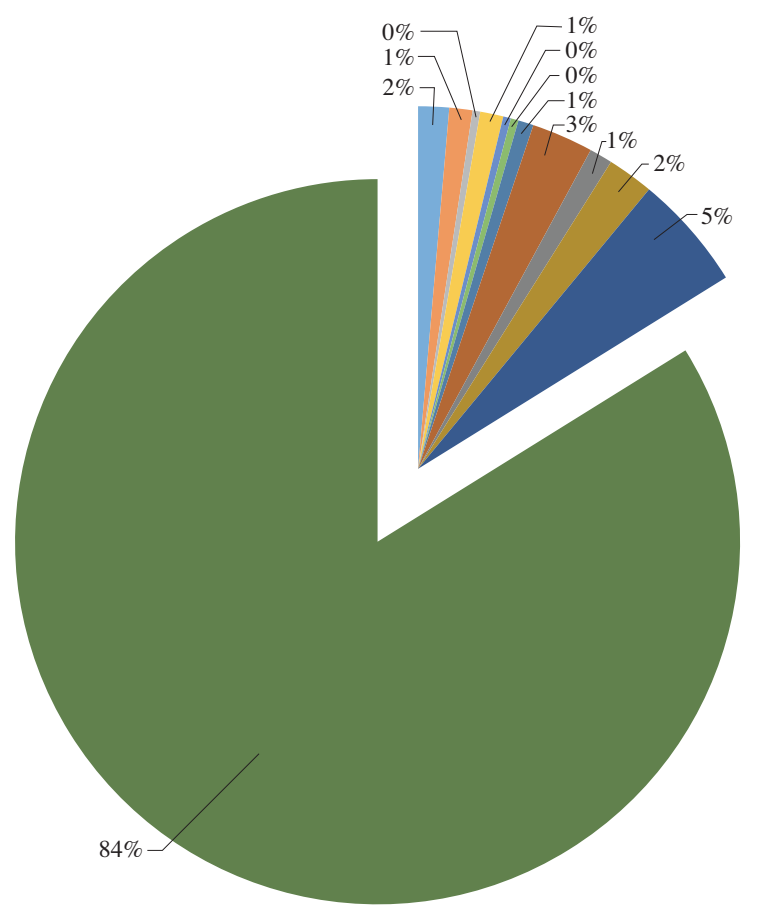

- Sentencias

- Ratificación de inocencia

- Condenatoria

- Principios de oportunidad

- Procedimiento abreviado

- Procedimiento directo

- Apelación

- Archivos

- Extincion del ejercicio de accion penal

- Instrucción

- Llamamieto a juicio

- Investigacion

Fuente: archivos de la Fiscalía de Morona Santiago, 2018.

este delito el $64 \%$ se encuentra en la búsqueda de evidencias que sustente el delito para continuar con el debido proceso. Han sido dos de los 39 casos investigados que han culminado las etapas procesales y han recibido una sentencia. Se conoce, además, que un porcentaje minoritario del $3 \%$ de los casos han sido archivados o no han presentado los suficientes elementos para una formulación de cargos en contra del procesado (gráfico 5).

El delito de ruptura de sellos es conocido como la conducta de los ciudadanos que lleva a retirar los sellos impuestos por la autoridad competente en medida de incumplimiento. A pesar de la gestión pública realizada para evitar la sanción en los ciudadanos, se conoce que en Morona Santiago existe un total de cuatro casos de los cuales el $75 \%$ se encuentran en el análisis de las pruebas necesarias para continuar con las etapas procesales y el $25 \%$ indagan en la instrucción fiscal, etapa en la que el fiscal expone ante el correspondiente tribunal penal la información de cada uno de los elementos que permite a la autoridad jurídica conocer sobre la responsabilidad del imputado en la comisión del delito (gráfico 6). 


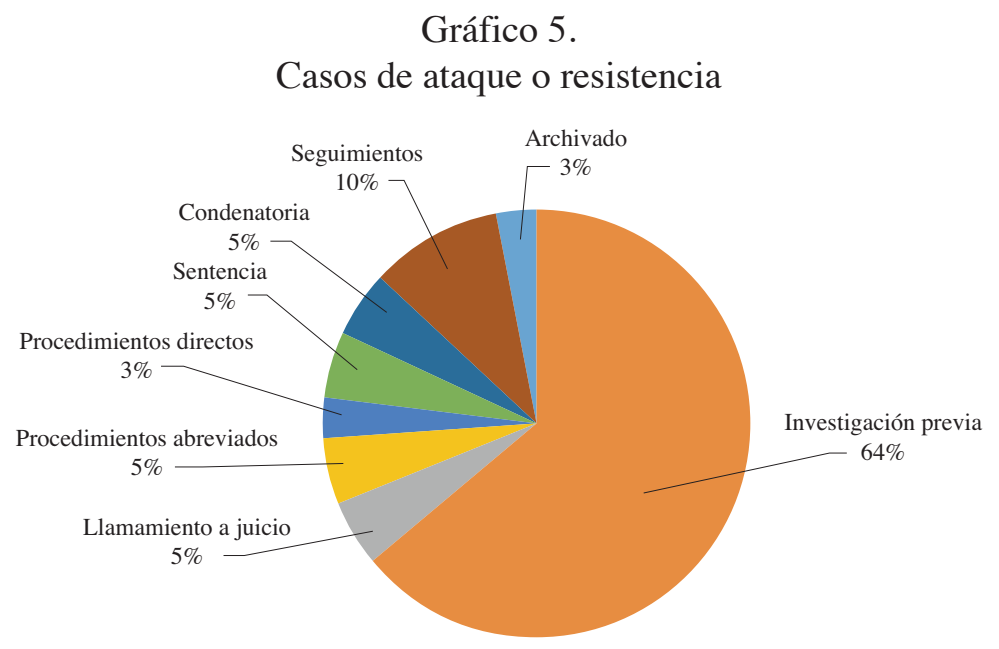

Fuente: archivos de la Fiscalía de Morona Santiago, 2018.

Gráfico 6.

Casos de ruptura de sellos

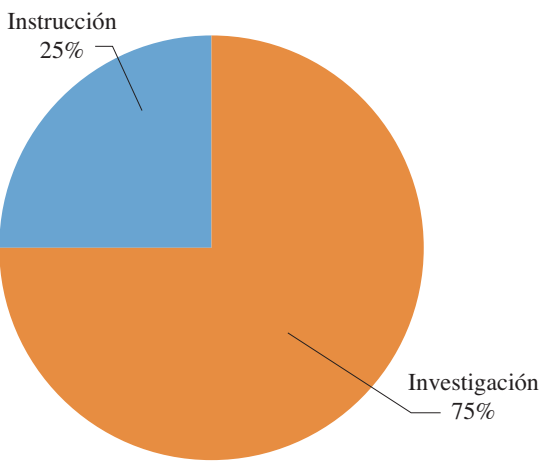

Fuente: archivos de la Fiscalía de Morona Santiago, 2018 .

\section{CONCLUSIONES}

La auditoría forense es reconocida como una herramienta empleada para la detección y la prevención de fraudes financieros. Por una parte, se orienta a la investigación de delitos financieros mediante la obtención de evidencias competentes que servirán de apoyo en los tribunales de justicia y, por otra parte, busca minimizar los riesgos para evitar fraudes a través del fortalecimiento del sistema de control interno.

En el estado ecuatoriano la investigación fiscal por delitos contra la administración pública puede iniciar mediante los informes de las auditorías financieras que emite la Contraloría General del Estado en las que se haya determinado indicios de responsabilidad penal y a través de las denuncias realizadas en las dependencias de la Fiscalía General del Estado. Con estos antecedentes se inicia una investigación fiscal para fundamentar los hechos que serán expuestos ante las salas de justicia a orden del juez correspondiente. En esta investigación, los delitos contra la administración pública en la provincia de Morona Santiago que han sido determinados por la Contraloría General del Estado mediante exámenes de auditoría financiera forense ha sido el peculado y el cohecho mientras que los delitos que 
han sido investigados bajo denuncia son el incumplimiento de decisiones de la autoridad competente, el ataque o resistencia y la ruptura de sellos.

El número de casos investigados en Morona Santiago de acuerdo con la cantidad de investigaciones iniciadas se presentan en el siguiente orden: 1) Incumplimiento de decisiones legítimas de la autoridad competente, 2) Ataque o resistencia, 3) Peculado, 4) Cohecho y 5) Ruptura de sellos. Sin embargo, únicamente trece casos de los 360 investigados se encuentran con sentencias, siendo siete por peculado, cuatro por ataque o resistencia y dos por incumplimiento a las decisiones de la autoridad.

De la investigación realizada se reconoce que la normativa legal ecuatoriana requiere mayores reformas para lograr que los infractores no se queden en la impunidad, siendo la Contraloría el ente de seguimiento a todos los juicios iniciados a partir de los informes de auditoría financiera que impliquen indicios de responsabilidad penal.

\section{REFERENCIAS BIBLIOGRÁFICAS}

Asamblea Nacional Constituyente (2008). Constitución de la República del Ecuador. Registro oficial n. 449. Quito.

Asamblea Nacional Constituyente (2016). Código Orgánico Integral Penal. Registro Oficial n. ${ }^{\circ} 180$. Quito.

Badillo, J. (08 de marzo de 2012). Auditoria forense. Recuperado de http:// www.vhgconsulting.com/auditoriaforense-3/
Benito, B., Guillamón, M., Ríos, A. y Bastida, F. (2018). Can salaries and re-election prevent political corruption? An empirical evidence. [¿Pueden los salarios y la reelección prevenir la corrupción política? Evidencia empírica]. Revista De Contabilidad, 21(1), 19-27. doi:10.1016/j. rcsar.2017.04.003

Camisón, J. y Moreno, S. (2018). 2016 and 2017 compliance reports on the recommendations proposed by GRECO for the prevention of judicial corruption in Spain: Chronicle of non-compliances. [Informes de resultados de 2016 y 2017 Sobre las recomendaciones propuestas por el GRECO para la pr. Teoría y Realidad Constitucional], UNED. Teoría y Realidad Constitucional, (41), 337-356. Recuperado de www.scopus.com

Cano, M. y Castro, R. (2004). Auditoría Forense. Medellín: Ecoe Ediciones.

Cárdenas, L. y Becerra, A. (2013). Rol del contador auditor, en la aplicación de la justicia. EE.UU.: Inter American Affairs.

Duarte, G. (2015). Importancia de la auditoría forense en las organizaciones del sector comercial en Colombia. Bogotá: Universidad Militar Nueva Granada.

Fontán, E. (2009). El impacto de la auditoría forense como técnica en la detección, prevención y control del fraude. Buenos Aires: Instituto de auditores forenses IDEAF.

Hortal, A. y Bautista, D. (2013). Ética para corruptos. Una forma de prevenir la corrupción en los gobiernos y administraciones públicas. Revista de Ciencias Humanas y Sociales, 70(136), 325-327. 
López,A. y Pesantez, C. (2016). Evaluación comparativa del sistema de control interno del sector comercial y del sector público del Cantón Morona. Revista Killkana Sociales, 1(1), 1-8.

Pérez, E. (2018). Public corruption: Concept and measurements. Towards public compliance as a criminal risks prevention tool. [Corrupción pública: Concepto y mediciones. Hacia el public compliance como herramienta de prevención de riesgos penales]. Política Criminal, 13(25), 104-143. doi: 10.4067/ S0718-33992018000100104.

Quintinilla, J. y Mendoza, T. (2015). Caracterización de las investigaciones sobre auditoria forense y corrupción en América. Revista Publicando, 4(2), 143-153.

Ramírez, M. y Bohórquez, J. (2013). Metodología y desarrollo de la auditoría forense en la detección del fraude contable en Colombia. Cuadernos de Administración, 29(50), 186-195.

Rey, J. (2016). Contabilidad y fiscalidad. Madrid: Nobel.

Rivadeneira, V. (16 de mayo de 2018). Tratamiento procesal para fraudes en el Consejo de la Judicatura. (E. d. UCACUE., entrevistador).

Salinas, R. (2014). Delitos contra la administración pública. Lima: Jurídica Grijley.

Torres, E., Jaramillo, C. y Cuenca, M. (2016). La auditoría forense, una herramienta de control en el sector público y privado del Ecuador. Revista Sur Academia, 1(5), 82-90.

Torres, J. (2013). Auditoria forense . Bogotá: Corporación Universitaria Minuto de Dios. 